\title{
Research of Oil Road Bitumen Modification with Low Density Polyethylene
}

\section{K. K.SYRMANOVA ${ }^{1,2}$, E.T. BOTASHEV ${ }^{1}$, D.B.TLEUOV ${ }^{1}$, M.T.SULEIMENOVA², A.A. ESHANKULOV ${ }^{1}$ and ZH.B. KALDYBEKOVA ${ }^{1}$}

${ }^{1} \mathrm{M}$ Auezov South Kazakhstan State University, Shymkent, Kazakhstan.

${ }^{2}$ Miras University, Shymkent, Kazakhstan.

*Corresponding author E-mail: syrmanova.kulash@mail.ru

http://dx.doi.org/10.13005/ojc/330155

(Received: November 15, 2016; Accepted: February 10, 2017)

\begin{abstract}
The aging of bitumen in the asphalt concrete pavement inevitably raises the question of the possibility of restoration of its regeneration characteristics. In general bitumen is classified as road bitumen, building bitumen, roofing bitumen, insulation bitumen, special purpose bitumen and others. Road bitumen is most produced (70-80\%) and intended for the production of all major types of construction and repair of road works, and also liquid bitumen intended to prolong the season of road works. A promising method to improve the quality of bitumen and road coatings is using the polymeric modifier, such as polymeric waste and secondary polymers such as polyethylene, polyethylene terephthalate, atactic polypropylene in bituminous compositions. Modifying bitumen with polymers enhances its elasticity, strength and heat resistance at elevated temperatures. Increasing the crack resistance of road surfaces, increases the lifetime. This article reviews the applications of the polymer components to improve the structural and mechanical properties of bitumen. The qualitative characteristics of bitumen can be restored with recycled polymeric materials such as polyethylene. Using polyethylene in the road mix composition improves the physical and mechanical properties of bitumen by improving the adhesion of bitumen with mineral components. This allows to considerably reducing the consumption of bitumen, which in turn enables to utilize a large-waste of polymer.
\end{abstract}

Keywords: bitumen, organic binding materials, modification, polyethylene, road construction.

\section{INTRODUCTION}

Road bitumen under aggressive environmental influences cannot always meet the desired quality requirements. For example the action of the temperature difference in summer and winter, the load deformation and so on. This leads to the fact that the service life of pavement is decreases. The global trend of road construction used has polymeric modifiers in road bitumen for many years. 
Production of high quality bitumen for road construction is becoming a promising direction. Bitumen is widely used in many industries, so their production is an important economic task and requires constant improvement. Today, the quality of produced bitumen and the volume of their production do not fully meet the market requirements.

There are naturally occurring bitumen, bitumen derived from reservoir rocks, and bitumen obtained in petroleum refining. Of all types of bitumen produced about $70-80 \%$ of road bitumen and are among the most common materials used in road construction. They are intended for the production of all major types of construction and repair of road works.

Bitumen has been used in road construction for over a century and plays a very significant role in all aspects of the properties of a road bed such as adhesion, temperature susceptibility, friction, aging resistance and durability. Due to the growing levels of traffic load on roads and changeable weather conditions, research to improve the properties bitumen has become increasingly important. Safety performance of pavement largely depends on the stability of the bitumen properties in time. The quality of the road surface largely depends on the quality of bitumen. For the construction of a durable coating is necessary to meet a number of properties of bitumen. The most important requirements to the pavement is its durability and crack resistance

The task is bitumen bonding mineral material particles together. In this bitumen should have good adhesion to masonry materials throughout the life of the structure when exposed to water. Increasing the viscosity of bitumen improves their adhesion to the surface of the mineral materials, but highly viscous bitumen used is not always advisable due to their increased brittleness.

The service life of the pavement is only $50-70 \%$ of the standard. Bitumen has a small temperature range of exploitation in a hot summer, and in winter, especially in areas with extreme continental climate. This limits the use of products. All these drawbacks result in reduced durability of bituminous materials. Significant improvement of bitumen properties can be achieved by introducing the polymer modifiers, which is obtaining bitumenpolymer compositions.

Table 1: Physico-mechanical characteristics of oil road bitumen 70/100

\begin{tabular}{|c|c|c|c|c|c|}
\hline \multicolumn{2}{|c|}{$\begin{array}{l}\text { Penetration, } \\
0,1 \mathrm{~mm} \text { at }\end{array}$} & \multirow{2}{*}{$\begin{array}{c}\text { Ductility, } \\
\mathrm{cm} \text { at } \\
25^{\circ} \mathrm{C}\end{array}$} & \multicolumn{2}{|c|}{ Temperature, ${ }^{\circ} \mathbf{C}$} & \multirow[t]{2}{*}{$\begin{array}{l}\text { Flash } \\
\text { point }\end{array}$} \\
\hline $25^{\circ} \mathrm{C}$ & $0^{\circ} \mathrm{C}$ & & Melting point & Brittle point & \\
\hline 75 & 22 & 115 & 48 & -20 & 240 \\
\hline
\end{tabular}

Table 2: Physico-mechanical characteristics of polymer-bitumen binders

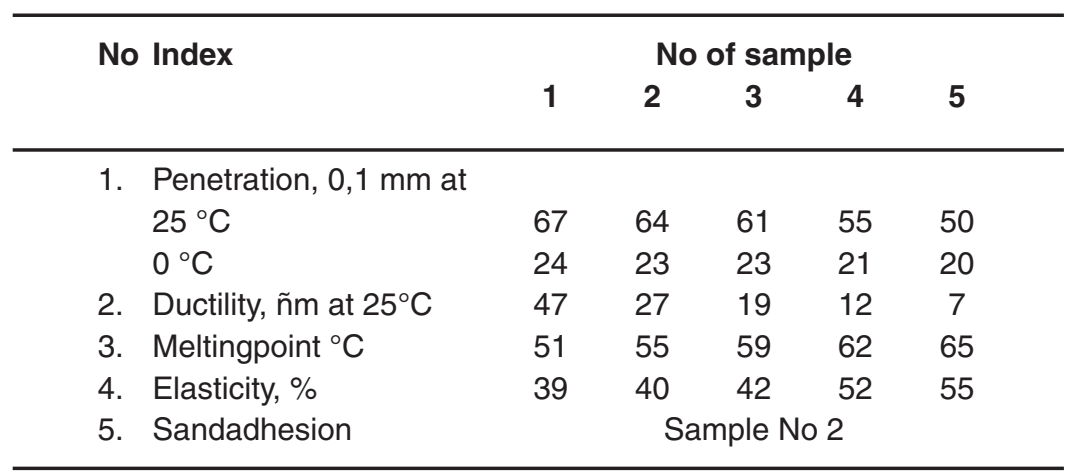


The use of polymer modifiers has been recognized as an appropriate solution for promoting the engineering properties of bitumen and asphalt mixes, but it is relatively a costly procedure for paving roads. From an environmental and economic point of view, the use of recycled instead of origin materials could have several advantages such as help easing landfill pressures and reducing demands of extraction from natural quarries. Furthermore, this would be an alternative solution for environmental pollution by utilizing waste materials as secondary materials in road construction projects.
Currently, the use of polymeric modifiers allows increasing heat resistance at elevated temperatures, and cracking resistance up to temperatures of minus $50-60^{\circ} \mathrm{C}$, to increase flexibility, improve adhesion properties, particularly with respect to the surface of acid rock materials and so on.

In the process of modifying the formation of a spatial net of polymer macromolecules in the structure of bitumen, bitumen giving some properties of polymers. Structural network strength is dependent on the strength of connections in the

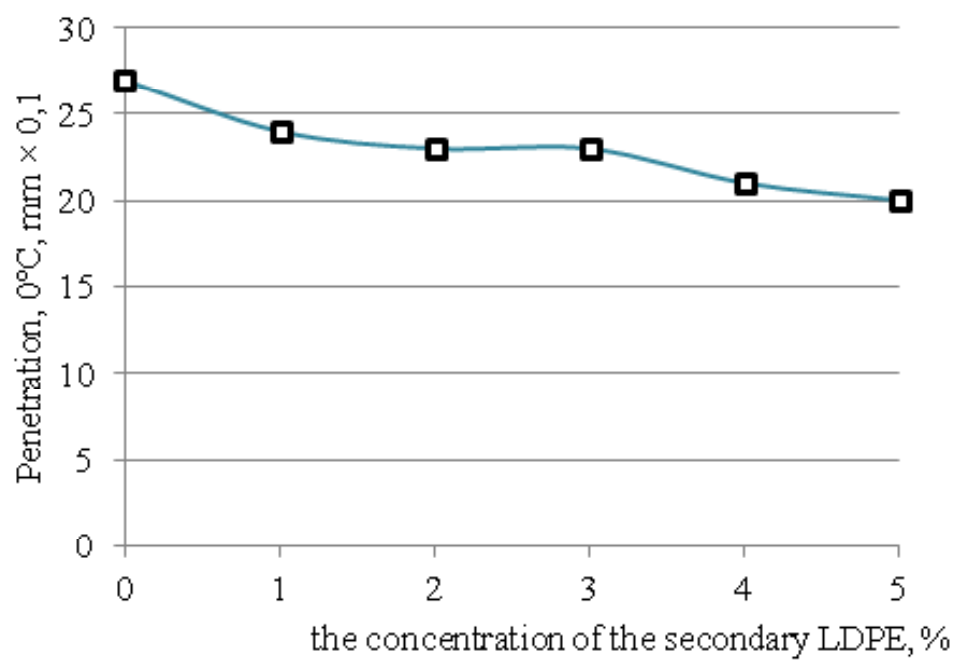

Fig. 1: The dependence of the penetration at $0^{\circ} \mathrm{C}$

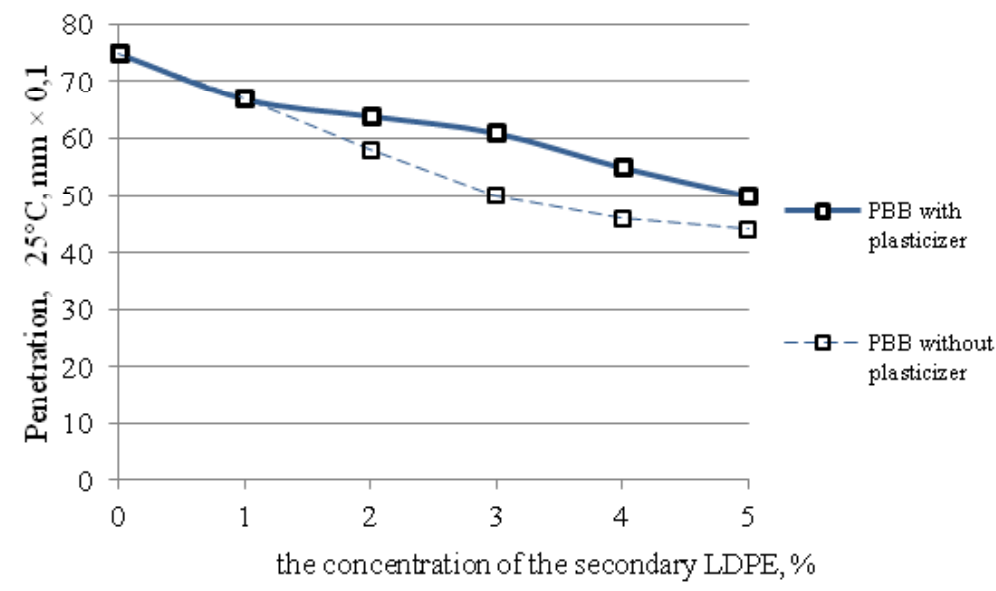

Fig. 2: The dependence of the penetration at $25^{\circ} \mathrm{C}$ 
grid nodes and the number of nodes. The elasticity of the structural grid depends on the flexibility of the chains between the nodes

One of the reasons for the appearance of cracks, shear, peeling and potholes in the pavement is the aging of the bitumen. The aging of bitumen is the totality of reversible and irreversible changes in its chemical composition and structural-mechanical properties occurring during storage, processing and recycling operation.

Main factors causing this aging are:

- Reaction of bitumen components with oxygen and water;
Temperature fluctuations;

- $\quad$ Catalytic effect of mineral materials surfaces of bitumen organometallic compounds;

- Infrared radiation and ultraviolet radiation impact;

Mechanical load.

Preparation of polymer-bitumen binders provide increased process temperature of about 150$200^{\circ} \mathrm{C}$ and an intensive mixing of the components.

When selecting a modifier for bitumen of secondary polymers, were set tasks such as effectiveness and efficiency of production technology, the use of readily available and traditional

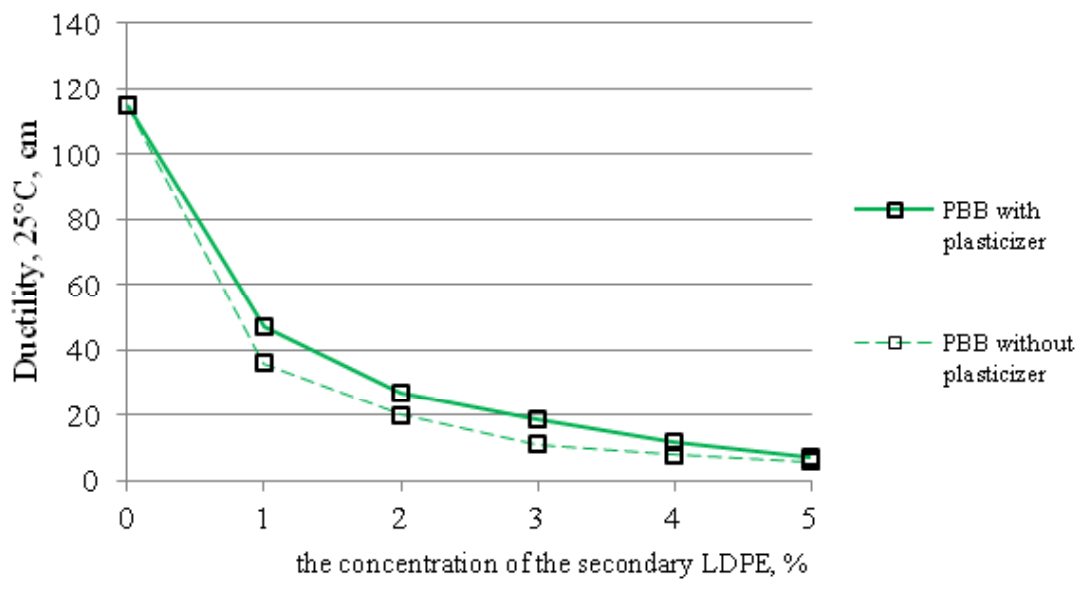

Fig. 3: The dependence of the ductility at $25^{\circ} \mathrm{C}$

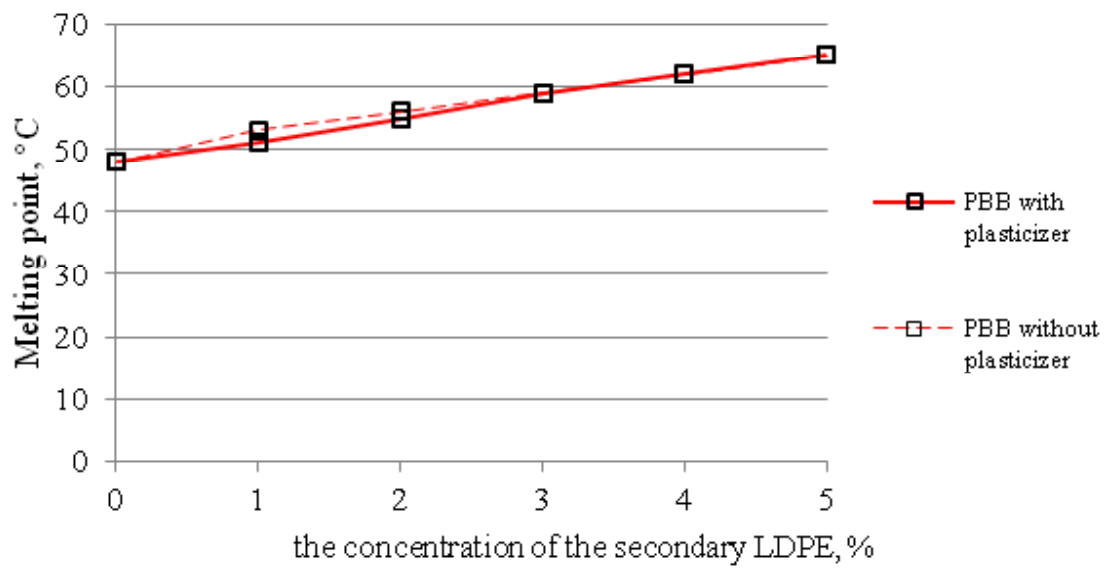

Fig. 4: The dependence of the melting point 
components of the mixture produced in our country, increase the quality characteristics of the resulting polymer-bitumen binders (PBB).

According to the comprehensive analysis for problem solving, research selected plastic waste, namely, plastic film, which is a secondary low density polyethylene (LDPE). Secondary LDPE unique polymeric material having valuable properties, produced in large amounts is well combined with bitumen, it contributes significant improvement in properties of the WSP and economically profitable. The largest application of LDPE are as film. PE waste is the most significant of all types of plastic waste.
Thesis purposes:

- Research of the secondary low-density polyethylene influence, used as a modifier, to the physico-mechanical properties of bitumen;

Development of a polymer-bitumen binders (PBB) producing method by modifying the bitumen with the secondary low density polyethylene;

Recommendations development of selection the optimal formulation of the polymerbitumen binders.

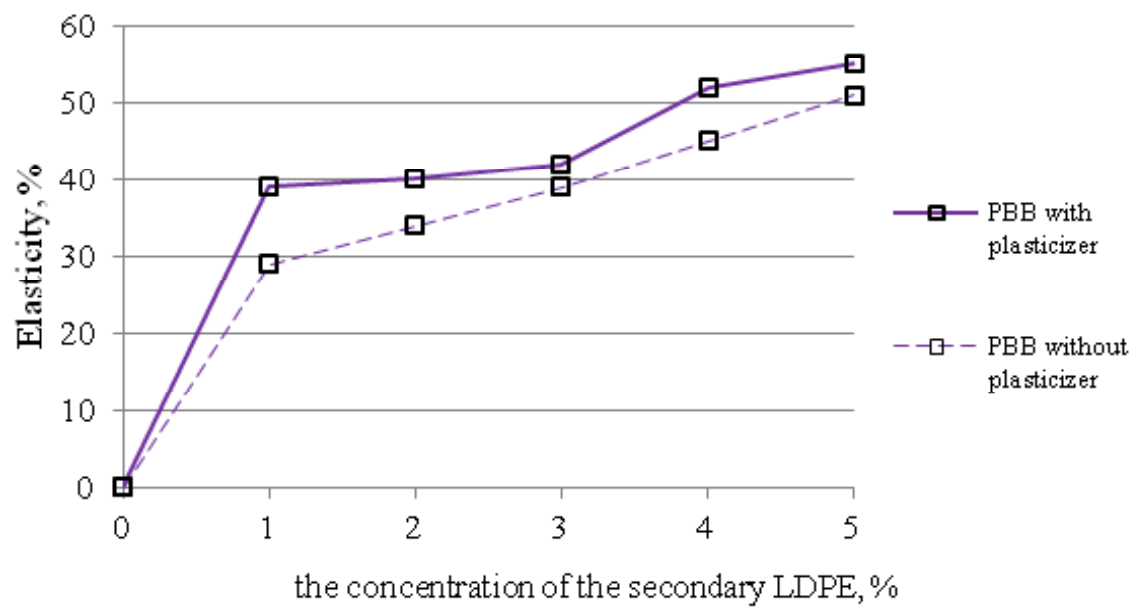

Fig. 5: The dependence of the elasticity

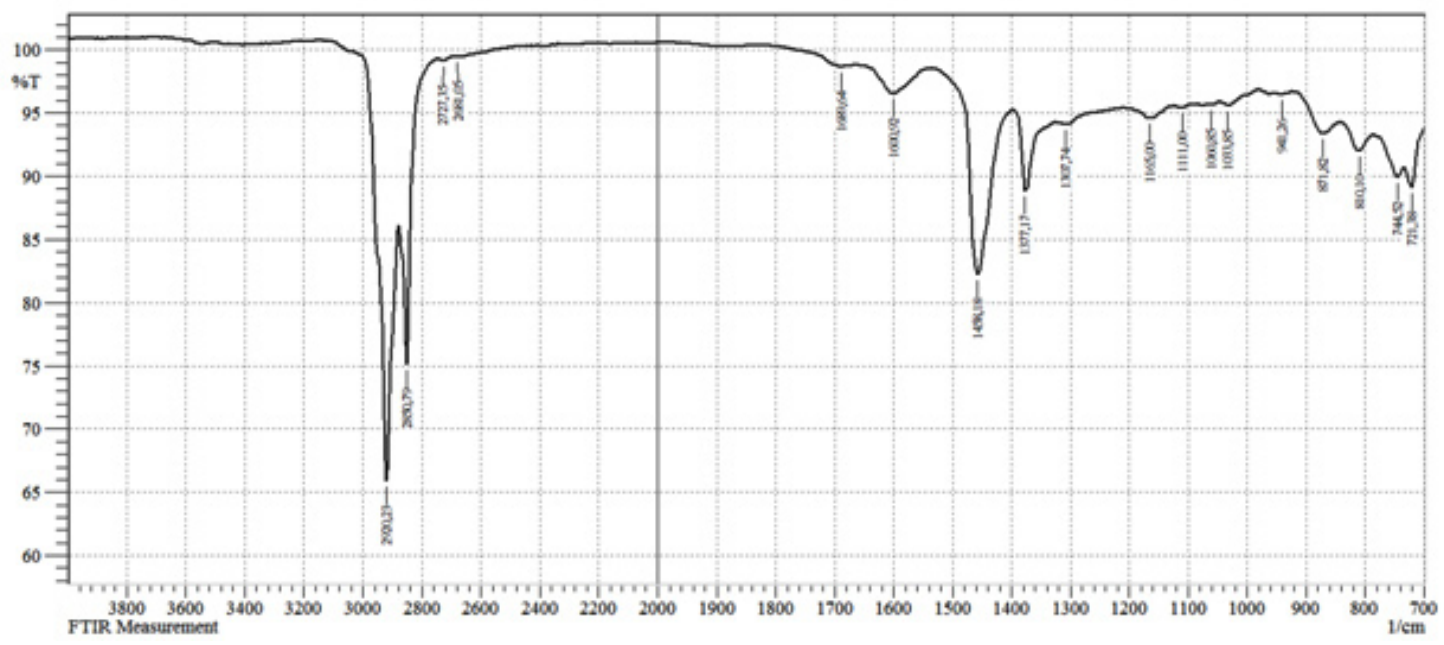

Fig. 6: IR spectrum of oil road bitumen $70 / 100$ 


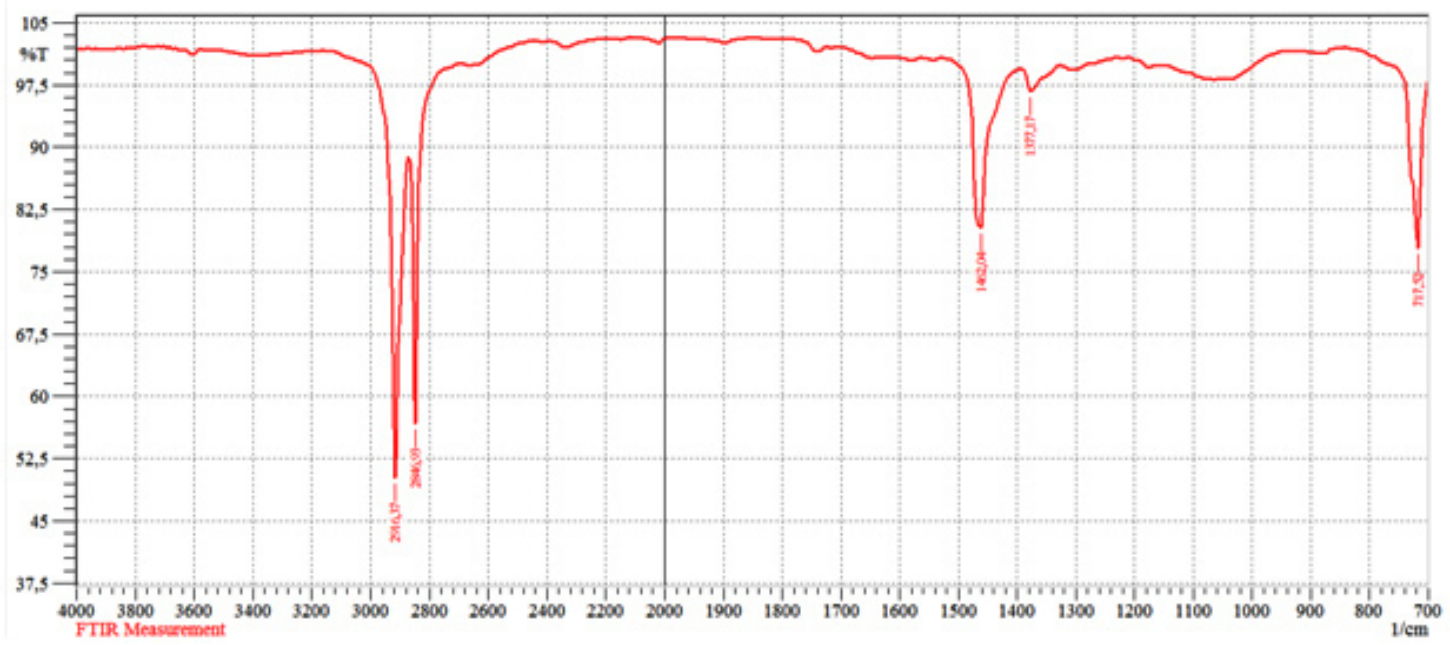

Fig. 7: IR spectrum of the secondary LDPE

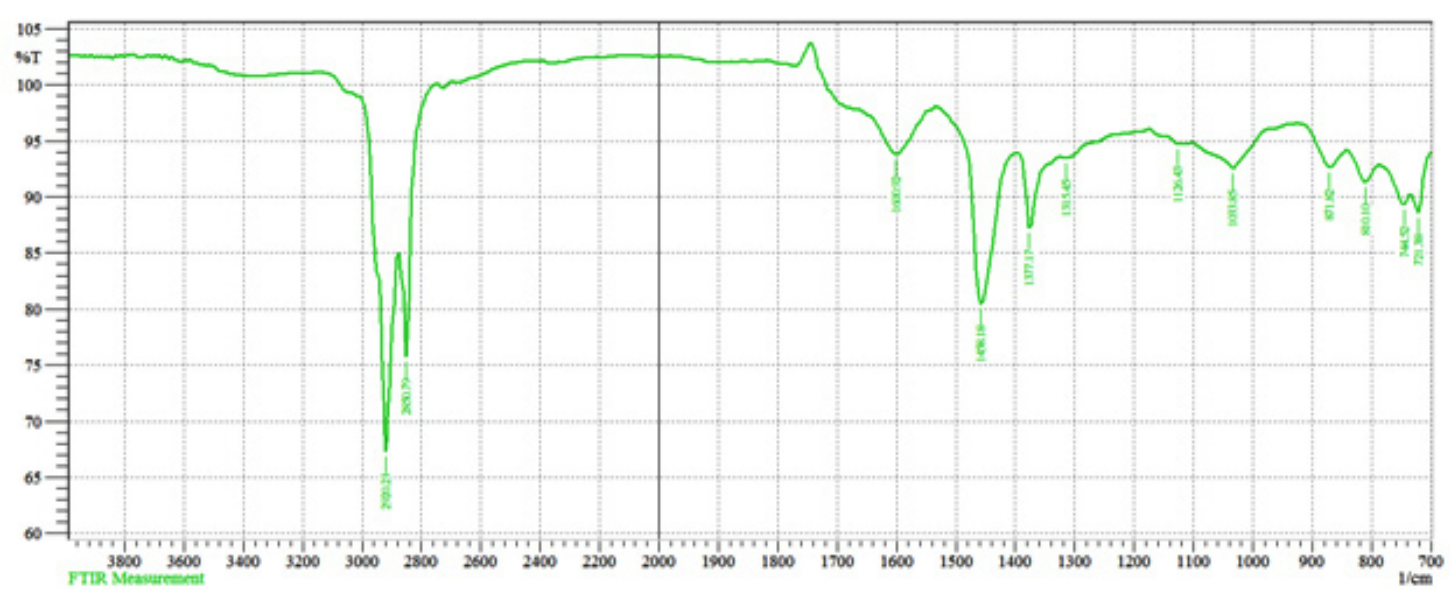

Fig. 8: IR spectrum of PBB with $1 \%$ secondary LDPE

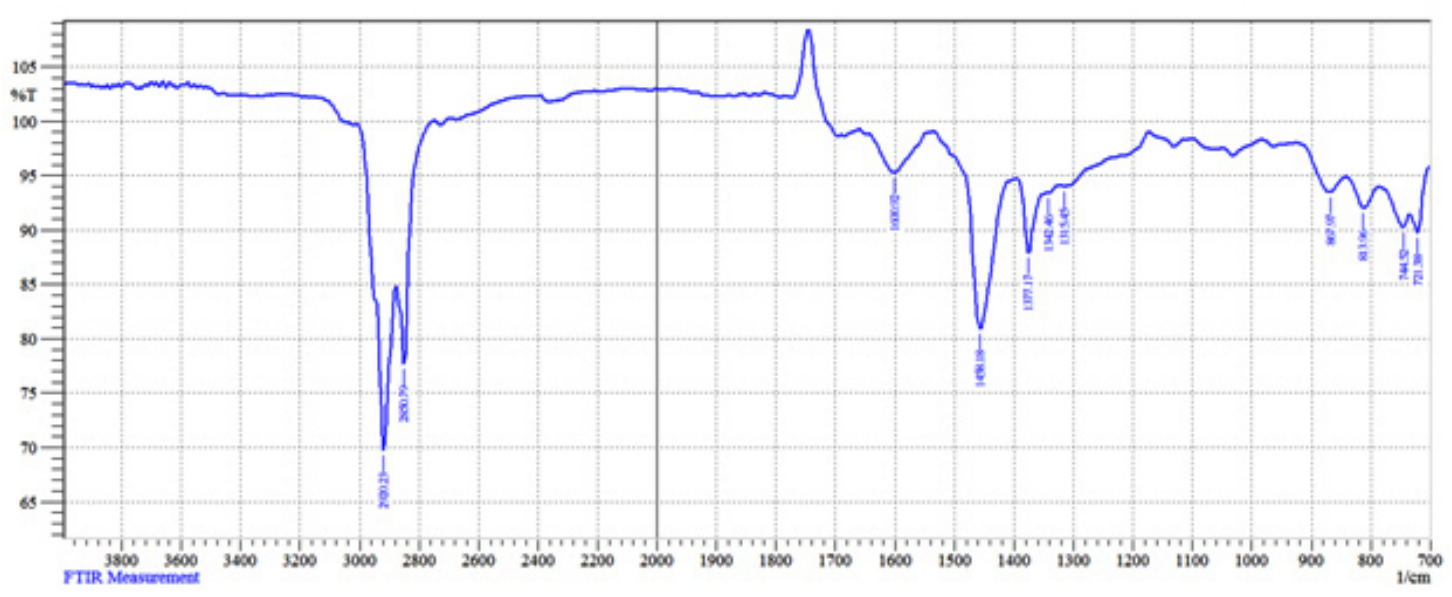

Fig. 9: IR spectrum of PBB with $3 \%$ secondary LDPE 


\section{MATERIALS AND METHODS}

The objects of research are:

1. The oil road bitumen 70/100.Oil road bitumen $70 / 100$ is a large-product of oil refining, has a complex of technical properties and is widely used in road construction.

2. Secondary LDPE - polyethylene film, previously used. In the secondary LDPE is used as a bitumen modifier. Prior to the modification process film was subjected to preliminary processing: washing with distilled water, drying and conversion into a homogeneous material in the form of flakes. The largest application of LDPE are as film.

3. Industrial oil I-20A. The paper used as a plasticizer. Oil I-20A is a distillate or a mixture of distillate and residual oil selective treatment. Oil I-20A is used as working fluids in hydraulic systems of machine equipment, automated lines, presses, for lubricating gears.

In bitumen is added $3 \%$ the plasticizer of the volume of the mass of bitumen. Further secondary LDPE is added in different percentage proportions in an amount of 1, 2, 3, 4, 5 mass $\%$ of the volume of the bitumen. Were prepared 5 samples according to the percentage content of the polymer mixture.
Used methods for determining of organic binding materials uniformity runoff on a stick, ductility, penetration, ring-and-ball softening point, adhesion with a sand, elasticity, brittleness temperature, Fourier-infrared spectroscopy.

Implemented method of combining the secondary low density polyethylene with the road bitumen 70/100 with the use of industrial oil I-20A as a plasticizer. Studied the structure of the obtained polymer-bitumen binders by Fourier-infrared spectroscopy.

According to Table 2 constructed the graphs of physico-mechanical properties of the samples with increasing content of the secondary LDPE in the bitumen, and also given for comparative analysis without plasticizer (Figure 1-5).

Studied the structure of the obtained polymer-bitumen binders by Fourier-infrared spectroscopy.Figure6-10 shows the IR spectra of the structures of the original bitumen, recycled LDPE and polymer-bitumen binders.

Study of IR spectra was found that in the process modification, occurs at elevated temperatures, there is significant peak changes in the area of $1033-1300 \mathrm{~cm}^{-1}$ of low density polyethylene and the resulting mixtures. This indicates the formation of structural compound in a dispersion medium of obtained PBB.

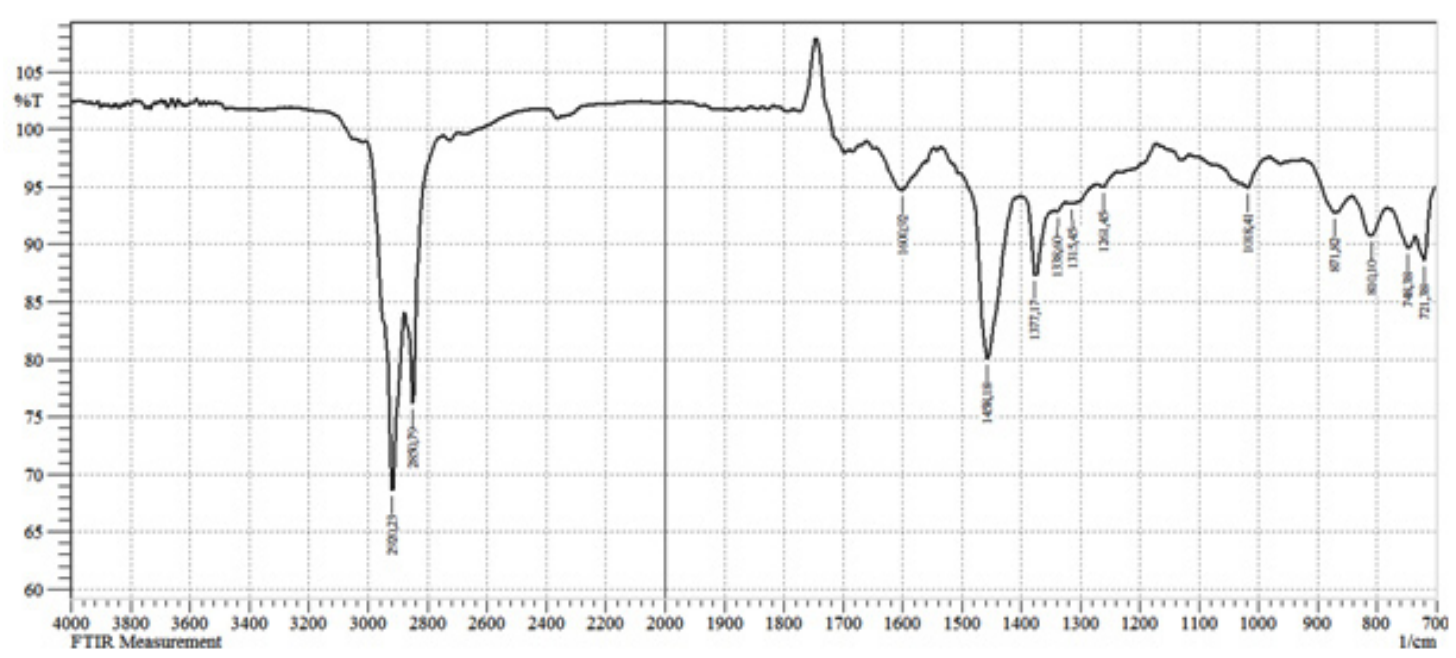

Fig. 10: IR spectrum of PBB with $5 \%$ secondary LDPE 


\section{CONCLUSIONS}

On the basis of the research the secondary LDPE used as the modifying all affect the specifications of the modified bitumen. Modifier additives to improve the structural and mechanical properties of the PBB.

Used more cost-effective process of producing polymer-bitumen binders with improved structural and mechanical characteristics. Modification of road bitumen with secondary low density polyethylene and production the polymerbitumen binders is economical and cost-effective.

Use of industrial oil as plasticizer allows allow better mixing of bitumen with the polymer, reduces the mixing time, an increase in mobility allows for the mixture to increase the strength and plastic characteristics, increase adhesion to mineral binder components. The use of the plasticizer increases the frost resistance of the PBB. On the totality of the best measures of physical-chemical and performance characteristics are most acceptable polymer-bitumen binders containing $3-4 \%$ recycled low density polyethylene and $3 \%$ of industrial oil I-20A.

Recycling of waste plastics is an important environmental issue. The use of secondary materials as additives for bitumen solves several problems: environmental, technological, quality improvement, increase the service life of road bitumen, economic.

\section{REFERENCES}

1. Galdina, V.D. Modified bitumens: training manual. 2009, 228

2. Bonchenko, G.A. Bitumen concrete. Shearresistant and modification technology by polymer. 1994, 176

3. La Mantia, F. Waste plastic recycling. 2006, 400

4. Gun R.B. Oil bitumens. 1973, 432

5. Gureev, A.A.; Chernysheva, E.A.; Konovalov,
A.A.; Kozhevnikova, Y.V. Oil bitumen production. 2007, 102

6. Gohman, L.M. Complex organic binders on basis ofSBS block copolymer. 2004, 510

7. Changqing Fang, Pei Liu, Ruien Yu, Xiaolong Liu. Preparation process to affect stability in waste polyethylene-modified bitumen. Construction and Building Materials, 54 (2014), 320-325 